\title{
Genetic Sequence Length
}

National Cancer Institute

\section{Source}

National Cancer Institute. Genetic Sequence Length. NCI Thesaurus. Code C135487.

The determination of the number of base pairs that compose a nucleotide sequence. 